\title{
THE ROUTLEDGE COMPANION TO INNOVATION MANAGEMENT
}

Edited by Jin Chen, Alexander Brem, Eric Viardot and Poh Kam Wong

5

\section{THE SYSTEMS APPROACH TO INNOVATION MANAGEMENT}

Magnus Karlsson and Mats Magnusson

(CC BY-NC-ND 4.0)

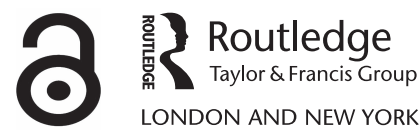




\title{
5
}

\section{THE SYSTEMS APPROACH TO INNOVATION MANAGEMENT}

\author{
Magnus Karlsson and Mats Magnusson
}

\section{Introduction}

The environment in which a company or organization operates today can be characterized by accelerating change, the globalization of markets, the emergence of new technologies and competitors, new regulatory requirements and ever more demanding users and citizens. In this environment, the ability to innovate becomes a key success factor for most organizations. They seek to continuously create and realize value by introducing new or changed products, services, processes, models, methods, etc.

The reasons for an organization to innovate are many and can include to increase revenues, growth and profitability, reduce costs and waste, increase the satisfaction of users, customers and citizens, motivate employees and attract partners, collaborators and funding, and so on. Engaging in innovation activities is thus a way for an organization to be future focused and effectively deliver on its overall objectives to secure prosperity and longer-term relevance and survival.

The ability to innovate and to make it a core organizational capability is increasingly becoming the most important differentiator and dominant success factor of organizations. Failing to capture new opportunities and to respond to innovation challenges may consequently lead to stagnation, irrelevance and ultimately to the demise of the organization.

\section{Why a systems approach?}

In their efforts to address opportunities and challenges, companies and organizations have been using many different innovation approaches. These include brainstorming sessions, idea management platforms, hackathons, design thinking labs, start-up accelerators and corporate venture funds, to name a few. Very often these efforts have not led to the desired innovation performance and they are therefore discontinued or they simply fade away. Some of the reasons for these efforts not living up to expectations can be the lack of necessary resources and competences, not setting a clear direction to guide creativity, failure in providing the required organizational structures, missing appropriate measurements, insufficient senior management commitment or the lack of providing appropriate end-to-end processes or ways of working for the innovation initiatives to succeed. 
Organizations are generally underestimating what it takes to make their innovation efforts successful, especially when they are seeking more radical, disruptive or transformative innovations. Innovation attempts tend to be fragmented, ad hoc and episodic. There is thus a need to find approaches that are more holistic, systematic and sustainable over time, and that changes the focus from singular events and projects to building longer-term innovation capabilities.

This chapter is addressing these issues by taking a systems approach to innovation management. Such an approach recognizes that the different activities and the support necessary for an organization to innovate are interrelated and interacting and can be managed more effectively as a system. This holistic view recognizes the systemic nature of innovation capabilities of an organization. The focus is on both removing barriers and putting enablers in place.

A systems approach can, for example, better guide the organization to assess and evaluate the innovation performance of the system and make adjustments with a focus on the most critical innovation capability gaps.

In this chapter, an exposition of systems-focused innovation management research and an overview of selected system-related innovation management frameworks from the literature provide the basis for a principled outline of an integrated framework for innovation management.

\section{Exposition of systems-focused innovation management research}

The field of organization studies and management has been enriched by systems theory for more than half a century. A key insight in this literature is that organizations can be seen as systems consisting of interrelated and interacting elements, where changes to one element of the system influence the whole. Hence, decisions need to be made based on holistic considerations, even if a complete understanding of systems is often beyond the bounded rationality of individuals (Simon, 1947). As Scott (1981) points out, the notion of systems used in organization studies has shifted over time, from a view of organizations as rational or natural systems, to the view of organizations as open systems that is commonly found today. A seminal work in this field is the one by Katz and Kahn (1966). Their contribution highlighted the view of organizations as open systems, having the capability to reduce entropy by exchanging energy with their environment. According to this perspective, organizations interact with their environment and need to continuously adapt to its changes.

Given the importance for organizations to respond to changes to their environment, the capacity to identify such changes and act upon them through learning and adaptation stand out as particularly important. This also underlines the importance of innovating in terms of changes to existing systems and their related behaviors. Some of the key concepts in systems theory can be used to explain the role innovation activities play in organizations, as well as some of their boundary conditions. In a stable environment, one of the important functions of an organization is homeostasis - constantly bringing the system back to its desired state. However, in order for an organization to survive in a nonstable environment, it must continuously adapt to changes in the environment. In order to do so in a sustained manner, an organization must have sufficient requisite variety (Ashby, 1956), implying that it must have a higher capacity to change and adapt than its surrounding environment. However, adaptation and change are dependent on energy, which must consequently be provided by productive behavior. Thus, we can regard an organization as a system handling certain productive functions, and innovation efforts modify these functions in order to fit the organization to its external environment. This is the core of Burns and Stalker's (1961) seminal work "Management of Innovation", in which they point out the different needs for innovating in environments with different dynamics and corresponding suitable ways of organizing. In a stable environment, the main focus of an organization is to 
perform defined tasks in an efficient manner, implying a mechanistic organizational structure. In a changing environment, on the contrary, the main focus of an organization has to be to adapt its tasks and output to match its changing environment, requiring an organic organizational structure (Burns and Stalker, 1961).

\section{Towards more adaptive and networked systems}

In order to match a changing environment, organizations need to continuously adapt their goals and hold control mechanisms that render such actions possible. This view is clearly reflected in the concept of homeorhesis proposed by Burgelman (1983). Burgelman regards organizations as continuously evolving systems, driven by both so-called induced strategic behavior (top-down) and autonomous strategic behavior (emergent changes driven bottom-up, often by innovation activities). This theory highlights the importance of emergent strategy (Mintzberg, Ahlstrand, and Lampel, 1998) in order to allow for sufficient adaptability under conditions where it is difficult to foresee developments and trends.

The difficulties in anticipating future development in the environment imply that innovation efforts do not only aim at adapting to change but that they can also change the environment indirectly through the organization. This also suggests that traditional strategic management frameworks have a somewhat limited usefulness for innovation purposes (see e.g. Brown and Eisenhardt, 1998) and that companies and organizations either need to include innovation activities as an explicit part of their strategies or complement them with an explicit innovation strategy.

Brown and Eisenhardt (1998) argue that dominant strategic management theories such as the positioning school (Porter, 1980) and the resource-based view (Wernerfelt, 1984; Barney, 1991; Grant, 1991) are both overly static. The focus in the positioning school is put on external factors and then, in particular, on analyzing competitive forces in order to identify positions where market imperfections can be used to make above-normal rents. Given the implicit focus on monopoly rents, relatively little attention is paid to innovation activities, apart from highlighting the need to make a choice between innovation followership and innovation leadership, respectively. Compared to the positioning school, the resource-based view (RBV) has a much closer relationship to both innovation and systems theory. Here, the view of rents is a Ricardian one, basically stressing that organizations have idiosyncratic resources and capabilities, and as a consequence, different performances. Apart from the key role played by resources and capabilities, other systemic characteristics such as values and systems are also addressed. An even stronger connection to the earlier mentioned works on organizations as systems is found in the work by Amit and Schoemaker (1993), who point out the necessity to combine a strictly internal focus on resources with the key industry factors represented in Porter's (1980) five forces framework. The matching of strategic assets and key environmental factors directly reflects the basic ideas about the necessity of fit between a system and its external environment.

As mentioned earlier, a clear shortcoming of both the positioning school and RBV is their limited attention to dynamics and change. Brown and Eisenhardt (1998) underline these frameworks' tendency towards statical optimization and argue for a new approach to strategic management with an emphasis on continuous reinvention and change. This focus on innovation activities and change is also found in the dynamic capabilities framework, which has sprung out of the RBV. The earliest works in this stream of literature introduced the notions of position, process and path to explain the dynamic capabilities that over time alter an organization's base of resources and capabilities (Teece, Pisano, and Shuen, 1997). Further development by Teece (2007) has combined traditional strategic management thinking with components from 
entrepreneurship theory, bringing in the importance of identifying and seizing opportunities as a fundamental part of a more emergent and innovation-oriented strategy. This view echoes the need for a more dynamic approach to strategic management. This is also reflected in works addressing innovation strategy and its relationship to business and corporate strategy. In particular, we here observe the notions of "competing for the future" (Hamel and Prahalad, 1994) and "discovery-driven planning" by McGrath (2010), where innovation efforts are seen as explicit parts of strategy.

Another observation is the need to address capabilities in a systemic manner, given that these tend to be constituted by bundles of resources, which are distributed throughout the organization and include substantial mutual interdependencies (Thompson, 1967). This implicitly calls for improved integration mechanisms (Lawrence and Lorsch, 1967; Bhidé, 2000) in order to purposefully bring together the increasingly heterogeneous resources of a larger system.

Altogether, we see that the systems perspective has a long tradition in organization studies, among other things highlighting systemic properties needed to cope with continuous change, adaptation and renewal. Also in strategic management theory it is possible to identify a stream of contributions emphasizing both the systemic nature of capabilities and the requirements in terms of dynamics. A notable limitation to the mentioned theoretical aspects is the clear focus on single organizations as the unit of analysis. Works with a somewhat more open view on development in the fields of organization and management emphasize the boundary-spanning nature of business and other value-realizing activities, explicitly focusing on systems larger than the single organization and the capabilities related to a networked way of working (see e.g. Lorenzoni and Lipparini, 1999). An innovation-related area of investigation addressing these questions is, without a doubt, open innovation (Bogers et al., 2017), which basically argues for a change of the systems boundaries considered by management with respect to innovations. By extending the innovation management focus to include suppliers, customers, users and collaborators, new opportunities can be identified, but at the cost of increased complexity. An even more explicit tendency to extend systems boundaries we see is the present interest in so-called innovation ecosystems (Adner and Kapoor, 2010). Although the "eco-" part of this concept may indeed be questioned, given fundamental differences between the biological world and the business world (Oh, Phillips, Park, and Lee, 2016), the explicit focus on systems can lead to new innovation insights.

The need to address interdependencies between internal resources and activities is frequently highlighted in existing literature on organizing and organizational learning. This is seen both in Senge's (1990) explicitly systemic view of organizational learning and in Nonaka's (1994) theory of organizational knowledge creation. The latter explicitly underscores the importance of typical systems theory constructs such as redundancy and requisite variety and how these factors influence innovation efforts. In the broad field of R\&D management the literature on multiproject management (Cusumano and Nobeoka, 1998) and portfolio management (Nagji and Tuff, 2012) also reflects a systems perspective by widening the management focus from singleinnovation projects to portfolios comprising sets of such projects and initiatives. An extension of this view has resulted in a focus on technology and other types of platforms, which today constitute a key factor in many industries and sectors.

\section{Structure, strategy and process perspectives}

As can be seen from the exposition of theory earlier, the use of a systems perspective in different streams of management research and thinking is not new but has been explicitly addressed and used in both strategic management, organization theory and design, as well as in project 
management, quality management, knowledge management and organizational learning, for example. Innovation management theory and practice can benefit greatly from building on this established wealth of knowledge. As stated already in the 1980s by Peter Drucker, we can conclude that innovating is a systemic practice (Drucker, 1985) and will thus benefit from insights from systems theory and thinking. Some authors (see e.g. Janszen, 2000) even go so far as to suggest that organizational innovation should be viewed as a complex self-adapting system. Many managerial systems are exhibiting systemic characteristics in terms of them being uncertain, interactive, nonlinear and distributed. This implies that they require real-time and dynamic coordination and integration of strategy, structure, process, culture and people (van de Ven, Polley, Garud, and Venkataraman, 1999). We will here summarize some of the main implications for innovation management from extant systems-focused theory in the broader management field. These insights are presented in relation to structure, strategy and processes, respectively.

\section{Structure}

In terms of structure, we need to consider both organizational structures and product structures, as well as their interrelationships. As pointed out by Henderson and Clark (1990), product architectures and organizational structures come to reflect each other, and this has implications for the innovations that organizations tend to generate. As a consequence, there is a need to actively design organizations so that they become more permeable for innovations, that is, by setting up ambidextrous structures (Tushman and O'Reilly, 1996). Important here is to enable not only the differentiation aspect of such solutions but also to manage the required integration through the use of suitable integration mechanisms. At the core of this issue we find the combination of exploitation of an organization's assets and the exploration of new knowledge and opportunities (March, 1991). At a certain point in time, revenues result from the match an organization makes between its existing strategic assets and the specific characteristics of its external environment (Amit and Schoemaker, 1993). However, this operative system needs to be continuously renewed in order to continuously have a good fit with a changing environment. Dynamic capabilities are used to revitalize this base of strategic assets, thus acting as a type of meta-capabilities, which are applied to existing operations and capabilities and thus indirectly contribute to short-term exploitation.

Another important implication from extant theory is the need to manage the overall portfolio of innovation projects and initiatives in a holistic and systemic way. The exact organizational design that should be used for this purpose needs to be based on an evaluation of available synergies between projects and the conflicting need for product and service integrity (Clark and Fujimoto, 1990). A frequently used approach to reconcile these different objectives is the use of product platforms or modularization. Depending on the specific needs, the use of one of these approaches, or their combination, may be appropriate (Magnusson and Pasche, 2014).

Recently, the organizing of innovation efforts has been subject to substantial changes, as increased connectivity and new business models create a tendency towards more open and collaborative ways of innovating. This has given rise to the notion of innovation ecosystems (Adner and Kapoor, 2010), which arguably in many cases is a more relevant unit of analysis than the single organization in order to understand how innovations are achieved. In this setting, the establishing of a fruitful technology platform (Cusumano and Gawer, 2002) often plays a fundamental role in achieving competitiveness through network externalities (see e.g. Schilling, 2010) and resulting complementarities. 


\section{Strategy}

Although there are numerous writings underlining the spontaneous and emergent nature of innovating, we would first of all like to challenge the reliance on such an ad-hoc approach. Even if a hands-off approach may historically have worked in a few companies and organizations, the changed situation in most workplaces makes this approach questionable today, as there is less time available to spend on innovation activities outside defined job roles and a more pronounced need for collaboration with others due to increased openness and multitechnology products, services and processes. Rather than leaving innovation success to chance, it is necessary to address innovation efforts in strategic terms, making innovation objectives explicit and shared and including mechanisms that can direct creativity to valuable areas and capture relevant bottom-up initiatives.

The field of strategic management has undergone a radical transformation in the last few decades. The strong focus on industries and competition seen in the positioning school (Porter, 1980) has gradually been complemented with a focus on distinctive (or core) capabilities (Barney, 1991; Grant, 1991; Prahalad and Hamel, 1990), leading to the need for combined and more systemic approaches, in line with the suggestions by Amit and Schoemaker (1993). As pointed out in the discussion on dynamic capabilities theory, managers "integrate, build and reconfigure internal and external competencies to address rapidly changing environments" (Teece, Pisano, and Shuen, 1997) to build sustainable or temporary competitive advantages. Following this view, innovation management can be viewed as a form of organizational capability, and as highlighted by Lawson and Samson (2001), organizations should thus focus on building innovation capabilities.

Another important development is the increased emphasis on dynamics (Brown and Eisenhardt, 1998; Teece, Pisano, and Shuen, 1997; Teece, 2007), leading to a closer and more bidirectional relationship between strategy and innovation activities. Consequently, there is a need to establish closer links between strategic management and innovation efforts, either in terms of innovation components in the strategies of the companies or organizations, or in terms of explicit innovation strategies.

\section{Process}

Innovation management has drawn upon process models and standards from adjacent management fields, such as product development management and quality management.

The development of an innovation always comprises a certain level of uncertainty, and this implies that there is a need for processes and ways of working that enable fast experimentation and adaptation. This does not exclude that planning is useful, but simply that a complete reliance on plans may lead organizations to miss out on innovations. Moreover, it is important to stay open to emergent insights, ideas and initiatives and align them with strategies as a complement to what is part of the induced strategy. This shift from planning to increased experimentation is clearly reflected in the change of dominant process models used in innovation and product development management. The well-established stage-gate model of Cooper (1990) has thus been complemented by other, more iterative and flexible approaches, such as agile development models, and lately also the use of so-called devops. Among these adaptive models for performing innovation activities we also note design thinking and lean startup. The process of design thinking usually involves the following steps: empathize, define, ideate, prototype and test. Unlike the stage-gate system that moves from idea to launch, design thinking starts by discovering customer needs (see e.g. Geissdoerfer, Bocken, and Hultink, 2016; Luebkeman and Brown, 2015). The 
lean startup (Erickson, 2015; Hart, 2012; Ries, 2011) approach to innovation management is another methodology that is gaining ground, especially in software-intensive industries. The lean startup methodology has emerged from the concepts of lean manufacturing and product development (Liker, 2004), agile software development (Cohen, Lindvall, and Costa, 2003) and customer development (Blank, 2013). The lean startup methodology uses a build-measure-learn process and in that way also has some similarities with design thinking. Apart from proposing a more iterative and agile way of controlling innovation activities than traditional development models, the mentioned approaches also share a clear focus on user and customer value and the need for experimentation to find this value. Hence, we can observe a shift from more resource-driven and push-oriented innovation models to more demand-driven and pull-based ones. These characteristics are also shared by lean approaches to product development and innovation activities (see e.g. Reinertsen, 1999), in which the cost of delays and the consequent need for innovation flow are underlined.

Summarizing the broad systems-based management literature with a high relevance for innovation management, we can conclude that there is a clear need for a systemic and systematic approach to guide innovation activities. Although we find numerous useful components in the extant management theory, we need to turn to more applied works in order to develop an applicable framework that can be fruitfully used in practice.

\section{Selected frameworks from the literature}

Around the 2000s, research shifted from a focus on individual processes, activities and elements to the integration of these elements into a system and the interactive relationships between them. As the scope of innovation management expanded to include multiple types of innovations, involving more and more stakeholders and drawing on a broader range of organizational capabilities, an integrative and systemic approach was required to ensure both the effectiveness and efficiency of innovation efforts of a company or organization.

The following is an overview of selected frameworks with a systems approach to innovation management. The overview does not have the ambition to be complete but to illustrate the diversity of frameworks that have been proposed during the last 20 years. The purpose is to extract common themes as an input to the framework outlined in the next section. The frameworks that have been surveyed have been developed in three main contexts: (1) academic works based on previous research or empirical studies, (2) national and international standardization activities based on the evolution of management systems and (3) practical experience and good practices from consultants and industrial research reports.

\section{Academic works}

In the context of academic works, the first edition of the popular textbook Managing Innovation (Tidd, Bessant, and Pavitt, 1997) provides a good starting point. The authors emphasize the inherently interdisciplinary and multifunctional nature of the management of innovation and propose a coherent framework based on the systematic analysis of the latest management research at the time. In short, Tidd et al. identified four generic phases of the innovation process: (1) scanning of the environment (internal and external), (2) deciding (on the basis of a strategic view) what signals to respond to, (3) obtaining the resources to enable the response and (4) implementing projects to respond effectively. To complete the framework, four clusters of behaviors or routines were suggested to support the process model: (5) taking a strategic approach to innovation 
efforts, (6) effective implementation mechanisms and structures, (7) supporting organizational context and (8) effective external linkages (Tidd, Bessant, and Pavitt, 1997).

The original framework has evolved but essentially stayed the same in subsequent editions (Tidd and Bessant, 2013), and similar frameworks have been put forward by, for example von Stamm (2003) and Goffin and Mitchell (2005).

The innovation management system proposed by Tuominen, Piippo, Ichimura, and Matsumoto (1999) had some similar elements but put a greater emphasis on customer needs and requirements and how technological opportunities can be matched to meet those needs. The system was influenced by the "fusion model" based on the works of Knut Holt (Holt, Geschka, and Peterlongo, 1984) and described in, for example, Muramatsu, Ichimura, and Ishii (1990).

A comprehensive research program with a focus on breakthrough innovation in established companies was conducted at the Rensselaer Polytechnic Institute. Approximately 30 large companies were studied during a 10-year period starting in 1995. The proposed management system for breakthrough innovation was made up of three distinct elements or sets of activities: (1) discovery with focus on conceptualization, (2) incubation with focus on experimentation and finally (3) acceleration with focus on commercialization. Each element has interfaces with one another and to the rest of the organization, and these relationships need to be managed by an overall orchestrating function. In a matrix-like structure, each element has its own expression of the innovation management system in terms of (a) structure and location, (b) mandate, (c) leadership and governance, (d) roles and responsibilities, (e) processes and (f) metrics (O'Connor, Leifer, Paulson, and Peters, 2008). The framework has been further elaborated based on additional research during the last 10 years (O'Connor, Corbett, and Peters, 2018).

The framework developed by the Center for Innovation Management Studies (CIMS) at North Carolina State University has a similar matrix-like structure but takes a broader scope and includes innovation management not only at the organizational level but also at the industry and macro-environment level. A comprehensive meta-analysis of innovation management research revealed key dimensions and competencies that successful innovating companies possess. The five elements or dimensions were strategy, organization and culture, processes, techniques and tools, and metrics. For each level and dimension, five management competencies were identified, forming a three-dimensional model: the management of ideas, markets, portfolios, platforms and projects (Mugge and Markham, 2013).

Another three-dimensional approach was developed by scholars at the Institute of Management Science \& Strategy of Zhejiang University. The total innovation management (TIM) framework was introduced in 2002 and was inspired by the resource-based view of organizations, complexity theory, and the works of Shapiro (2001), Bean and Radford (2001) and Tucker (2002), among others. The first dimension of the framework outlines different types of innovations as sources for competitive advantage: (1) technology innovation is the foundation, supplemented with (2) marketing, (3) organizational and (4) institutional innovation, and all are supported by the elements of (5) strategy and (6) culture. The second dimension emphasized the broad involvement of all (7) people in innovation activities in the organization. The final dimension extends the framework in time and space, indicating that innovation activities are actually executed all the time and everywhere ( Xu,Yu, Zheng, and Zhou, 2002; Xu, Chen et al., 2007). The framework has been applied in several empirical studies of companies in China (Chen, Jin, He, and Yao, 2006; Xu, Zhu, Zheng, and Wang, 2007), the United States (Menke, Xu, and Gu, 2007) and Japan (Mao and Wang, 2012).

The TIM framework has been further extended by Chen, Yin, and Mei (2018) to include a strategic vision with a focus on purpose and meaningfulness, forming a holistic innovation system. 


\section{National and international standardization}

The concept of management systems emerged in the context of standardization during the 1980s. The International Organization for Standardization (ISO) published the first version of the ISO 9000 series of standards in 1989, based on the philosophy of quality management developed since the 1950s. Quality management systems introduced the process-based view of the organization and the plan-do-check-act cycle for continuously improving the system, see ISO 9001 (ISO, 2015).

In parallel, the British Standards Institute (BSI) published the first standard for design management in 1989 that was developed into a series of design management system standards in the following years. BS 7000-1:2008 Part 1: Guide to managing innovation was published in 1999 (BSI, 2008). The standards were developed based on the concept of total design, a structured process for product design and development introduced by Stuart Pugh in the 1980s (Hollins, 2000).

Standardization activities in the area of innovation management started in the late 1990s. Requirements of a research and development and innovation (R\&D\&I) management system were developed by the Spanish Association for Standardisation and Certification (AENOR). The first management system standard, UNE 166002, was published in 2002 for a trial period, followed by the definitive requirement standard in 2006 (Mir and Casadesús, 2011; AENOR, 2006).

The standard included a development of the original innovation model of Kline (1985), had linkages to the British standard on managing innovation (BSI, 2008) and was designed by analogy with the international quality management system standard (ISO 9001). The Spanish standard was adopted and modified by several countries, including Portugal, Mexico and Brazil (Mir and Casadesus, 2011; Caetano, 2017). Several studies of Spanish companies have been made looking at the impact of the standard, for example, Mir, Casadesús, and Petnji (2016);Yepes, Pellicer, Alarcon, and Correa (2016); and Garechana, Río-Belver, Bildosola, and Salvador (2017).

In 2007, initiatives were taken by the European Committee for Standardization (CEN), which resulted in the creation of a technical committee on innovation management in 2008 , led by AENOR. The committee published a technical specification: Innovation Management - Part 1: Innovation Management System, in 2013, CEN/TS 16555-1:2013 (CEN, 2013; Caetano, 2017).

The ISO set up a committee (ISO/TC 279) for innovation management in 2013, led by the French secretariat of AFNOR (the French Association for Standardization). Like the approach taken at the European level, the aim was to develop guidance standards that provided recommendations rather than requirements. The first international management system standards for innovation management will be published in 2019.

Rebelo, Santos, and Silva (2015) discuss the possibilities for organizations to establish an integrated management system (IMS), incorporating different individual management system standards (MSS), including an innovation management system.

\section{Consultants and industrial research reports}

Another context for the development of the systems approach to innovation management is constituted by the consultants and industrial research reports, which are mainly based on practical experience and good practices.

Based on the practices of the consulting company Strategos and the thinking of Gary Hamel, Skarzynski and Gibson (2008) outlined a systems approach to innovation management in their book Innovation to the Core. Four main groups of elements are suggested: (1) leadership and organization, (2) processes and tools, (3) people and skills and (4) cultures and values. 
The Boston Consulting Group suggested a similar approach, focusing on innovation strategy, research and product development processes and a comprehensive set of organizational enablers (Taylor and Wagner, 2014). Other examples are software companies Microsoft and SAP, which have published their versions of frameworks (Microsoft, 2013; Cigaina, 2013).

A comprehensive effort to develop an innovation management standard was undertaken by the Total Innovation Management (TIM) Foundation (different from the TIM framework discussed earlier and independent of the work by ISO). The set of documents was described as an advisory standard with a maturity model and a management system approach and was published through the Product Development and Management Association (PDMA) in 2013 (PDMA and TIM, 2013).

Badrinas and Vila (2015) used the PDMA and TIM framework, with adaptations based on Vila and Munoz-Najar (2002), in an empirical study of six successful European companies. Seven "steps" were identified, together forming an integrated innovation management system: (1) management commitment, (2) stakeholders' influence, (3) statements: mission, vision and values, (4) strategy and objectives, (5) management review and communications, (6) people and competences, and (7) front-end innovation drive.

A system-related framework was developed in 2013 by the Japan Innovation Network (JIN) following a research committee report by the Ministry of Economy, Trade and Industry (METI) in Japan. The Innovation Compass framework was launched in 2014 and was based on a "twolayered management" model - the systematic approach to managing creativity and productivity in parallel in an organization. In the framework, three process elements: (1) idea generation, (2) business model building and (3) commercialization, are implemented through (4) training programs, (5) acceleration programs and (6) networks. The system is governed by top management through (7) a vision, goals and performance indicators, and implemented using (8) a supporting mechanism, including e.g. knowledge management (Nishiguchi and Konno, 2018).

As a final example, in the context of the European Foundation for Quality Management (EFQM), an innovation capability assessment framework was developed. The framework included several elements discussed earlier but put a specific focus on data analytics and management style (Hakes, 2014).

\section{Common themes}

As seen from the earlier discussion, a number of system-related frameworks for innovation management have been proposed in the literature during the last 20 years. See Table 5.1 for an overview of the 19 selected frameworks that have been discussed in this chapter.

A review of the frameworks reveals a number of common elements that should be considered by a company or organization for successfully achieving innovation. These elements can be categorized into eight themes: context, direction, leadership, culture, processes, structures, support and resources, and evaluation. Table 5.2 provides examples of elements for each theme based on the literature review.

\section{Principled outline of an integrated framework for innovation management}

It is beyond the scope of this chapter to make a comprehensive synthesis of the reviewed literature and propose a definitive framework for innovation management. As seen from the review, the system-related frameworks are evolving as more and more knowledge from research and practice become available. The scope and purpose of such frameworks are also changing over 
Table 5.1 Overview of selected system-related frameworks for innovation management introduced between 1997 and 2018

\begin{tabular}{|c|c|}
\hline Framework & References \\
\hline Innovation Management Process Model & Tidd, Bessant, and Pavitt (1997) \\
\hline Product Innovation Management System & Tuominen, Piippo, Ichimura, and Matsumoto (1999) \\
\hline $\begin{array}{l}\text { Requirements of an R\&D\&I Management System, } \\
\text { UNE 166002:2002/6 }\end{array}$ & AENOR (2006), first published 2002 \\
\hline Total Innovation Management & $\begin{array}{l}\text { Xu, Yu, Zheng, and Zhou (2002); Xu, Chen et al. } \\
\text { (2007) }\end{array}$ \\
\hline Bettina von Stamm (BvS) Innovation Framework & von Stamm (2003) \\
\hline Innovation Pentathlon Framework & Goffin and Mitchell (2005) \\
\hline Management System for Breakthrough Innovation & O’Connor, Leifer, Paulson, and Peters (2008) \\
\hline Innovation to the Core & Skarzynski and Gibson (2008) \\
\hline $\begin{array}{l}\text { Innovation Management System, CEN/TS } \\
\text { 16555-1:2013 }\end{array}$ & CEN (2013) \\
\hline Innovation Management Standard & PDMA and TIM (2013) \\
\hline Microsoft's Innovation Management Framework & Microsoft (2013) \\
\hline Innovation Management Framework, by SAP & Cigaina (2013) \\
\hline $\begin{array}{l}\text { Innovation Management Framework, by the Center } \\
\text { for Innovation Management Studies (CIMS) }\end{array}$ & Mugge and Markham (2013) \\
\hline $\begin{array}{l}\text { Innovation as a System, by Boston Consulting } \\
\text { Group }\end{array}$ & Taylor and Wagner (2014) \\
\hline $\begin{array}{l}\text { Innovation Compass, by Japan Innovation } \\
\text { Network (JIN) }\end{array}$ & Nishiguchi and Konno (2018) \\
\hline $\begin{array}{l}\text { Innovation Capability Assessment Framework } \\
\text { (EFQM) }\end{array}$ & Hakes (2014) \\
\hline Integrated Innovation Management System & Badrinas and Vila (2015) \\
\hline Holistic Innovation & Chen,Yin, and Mei (2018) \\
\hline Innovation Management System & O’Connor, Corbett, and Peters (2018) \\
\hline
\end{tabular}

Table 5.2 Examples of system elements for each theme of the framework for innovation management

\begin{tabular}{|c|c|}
\hline Theme & Examples of elements \\
\hline Context & $\begin{array}{l}\text { Scanning of the external and internal environment. Identification of trends, } \\
\text { opportunities and challenges, technologies, user and customer needs and requirements, } \\
\text { and stakeholders. }\end{array}$ \\
\hline Direction & $\begin{array}{l}\text { Vision and direction, managerial goals, objectives and strategies. Strategic and tactical } \\
\text { planning. }\end{array}$ \\
\hline Leadership & $\begin{array}{l}\text { Commitment, mandate, engagement, future focus and communication. Incentives, } \\
\text { leadership styles and values. }\end{array}$ \\
\hline Culture & $\begin{array}{l}\text { Work environment, social context, values and organizational culture supporting } \\
\text { innovation activities. }\end{array}$ \\
\hline Processes & $\begin{array}{l}\text { Innovation processes, including insights from the context, idea generation, prioritization } \\
\text { and selection, validation, experimentation and prototyping, business modelling, } \\
\text { incubation, commercialization and implementation. Innovation projects, initiatives and } \\
\text { portfolios. }\end{array}$ \\
\hline Structures & $\begin{array}{l}\text { Organizational setup, governance, roles and responsibilities. Internal and external } \\
\text { linkages, networks and collaboration (customers, partners, suppliers, etc.). }\end{array}$ \\
\hline $\begin{array}{l}\text { Support and } \\
\text { resources }\end{array}$ & $\begin{array}{l}\text { Funding, people and time. Tools and methods, competences and skills. Intellectual } \\
\text { property management and data analytics. }\end{array}$ \\
\hline Evaluation & $\begin{array}{l}\text { Innovation metrics, indicators, monitoring, assessment, evaluation, management review, } \\
\text { feedback. Improvement of the system. }\end{array}$ \\
\hline
\end{tabular}


time. However, a few key observations that are relevant for future research and practice can be made. These observations taken together can be summarized by a principled outline of an integrated framework for innovation management (see Figure 5.1).

The purpose of such a framework is to ensure the sustained buildup of renewal capabilities and continuous creation and realization of value for the organization and its stakeholders. It is argued that the proposed outline is fulfilling the general criteria of a well-functioning system: (1) comprehensiveness: all the necessary elements are included to achieve the purpose of the system, (2) coherence: all the elements are contributing to the same purpose, and (3) consistency: elements are aligned and are not conflicting.

\section{Management systems of the organization}

For the purpose of this summary, innovation management is considered at the level of the organization, based on the notion that the organization can control its own destiny (i.e. can be managed as an autonomous entity). The systems approach can be applied to any organization, public or private, of any size and in any sector. It can be used also for a set of organizations if they can be managed as one entity to a certain degree.

Based on the discussion earlier, two management systems of the organization are considered: the system for managing operations and the system for managing innovations (see for example March, 1991; Tushman and O'Reilly, 1996; Martinich, 2004; Nishiguchi and Konno, 2018). The systems are interrelated and interacting and can be implemented in one integrated or two separated hierarchies. They represent two modes of operation that require different adaptations and approaches to the themes: context, direction, leadership, culture, processes, structures, support and resources, and evaluation.

The system for managing operations is operating under conditions of relative certainty and decision-making can generally be based on knowledge and facts. The system is primarily

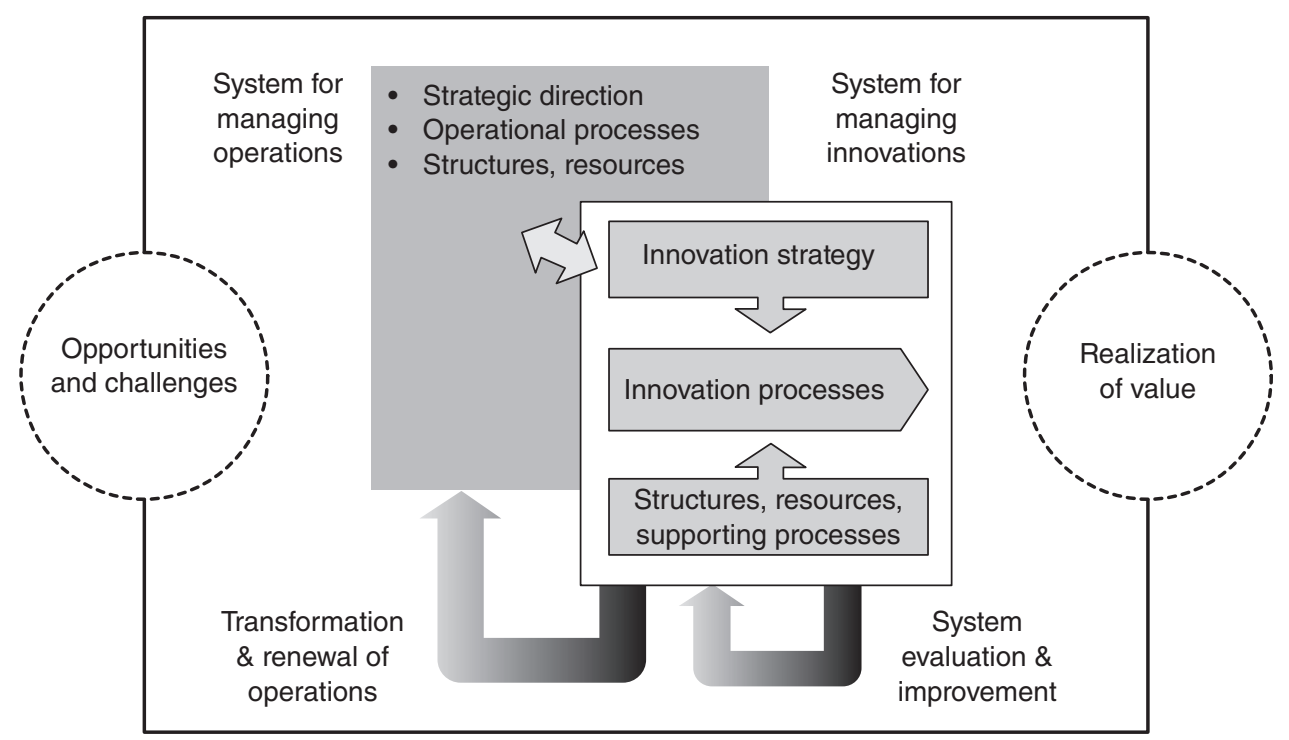

Figure 5.1 Principled outline of an integrated framework for innovation management 
designed to support existing offerings, processes and value realization models for existing markets, customers and users.

The system for managing innovations is operating under conditions of higher uncertainty, and decision-making must therefore to a large degree be based on assumptions. Uncertainties can relate to any dimension of the innovation or the innovation process, for example, strategic fit, feasibility to realize, cost and resources, value for the user, etc. The system is primarily designed to introduce new offerings, processes and value realization models, targeting existing as well as new markets, customers and users.

\section{Elements of the system for managing innovations}

Both management systems are dependent on effective and timely scanning and identification of opportunities and challenges of the context. The scanning, scanning can, for example, reveal new technologies, new user patterns and needs, as well as new customers, partners, competitors and other stakeholders. The context can also include issues internal to the organization related to assets, competences and other capabilities.

The direction for innovation activities, based on an understanding of the context, can be defined in terms of innovation objectives and one or more innovation strategies. An innovation strategy is typically designed both to contribute to and to challenge and extend beyond the overall strategic direction of the organization. The strategy can help to allocate resources and to ensure that innovation opportunities can move between the two management systems, depending on where they can be most effectively addressed.

Leadership commitment at different levels of the organization plays an important role in executing the strategy by inspiring and engaging people, promoting internal and external collaboration, balancing incentives and recognition for exploration and exploitation, communicating and creating awareness and fostering a culture supporting innovation activities, including risk taking and learning from failures.

Innovation processes are designed to achieve innovations according to the innovation strategy. Innovation initiatives in the form of projects, programs, etc., are implemented through these processes and may constitute one or more innovation portfolios. A set of generic innovation processes can be identified: (1) seek insightful knowledge to identify opportunities, (2) generate concepts and solutions based on these insights, (3) validate the concepts using experimentation and prototyping for example, (4) develop concepts into mature solutions and (5) deploy solutions to realize value. Deployment also includes capturing feedback from the diffusion of the innovations as well as lessons learned to improve the management systems.

The mentioned processes can be viewed as learning processes, designed to manage uncertainty by systematically converting assumptions into knowledge. They can be configured in different sequences, be executed iteratively, be implemented both internally and externally to the organization and be a combination of processes related to the system for managing operations and to the system for managing innovations.

Organizational structures are supporting and contributing to the innovation processes. Separated structures can be considered when the organization is aiming for innovations that are disruptive with respect to, or may be competing with, existing offerings, or when support and resources need to be protected from the influence of existing operations of the organization. Structures can involve external stakeholders, as in the case of collaborative, open or ecosystem innovation.

Resources that are necessary for facilitating the innovation processes can include people, time, funding, knowledge and infrastructures. Examples of other relevant support are tools and 
methods, competence development, knowledge management, strategic intelligence, portfolio management and intellectual property management.

\section{Performance evaluation and feedback processes}

A set of indicators can be established at different levels and for different parts of the systems for evaluating the overall performance of the organization. The evaluation can be related to the innovation performance of the organization, that is, the measurable results of innovation activities, or the innovation capabilities of the organization, that is, its ability to perform innovation activities in relation to its purpose and objectives.

Two feedback processes are important to consider within and between the two management systems of the organization. The system for managing innovations is evaluated and improved related to all its elements (i.e. context, direction, leadership, culture, processes, structures, support and resources, and evaluation). This feedback process is designed to continuously improve the system both in terms of efficiency and effectiveness.

The second feedback process captures learnings from the system for managing innovations and provides input to the renewal and transformation of the system for managing operations. In this way, the two systems are continuously evolving while adapting to changes external and internal to the organization (see Figure 5.1).

\section{Implications and conclusions}

\section{Implications for future research}

This chapter provides a broad exposition of systems-oriented management works, with the aim of deriving implications for management theory and practice through the principled outline of an integrated framework for innovation management. Given the abundance of systems-based management theories, it is not possible to perform a truly comprehensive review in a short chapter like this, but the selected literature should merely be seen as a way of deriving important characteristics that an integrated innovation management framework needs to include. Hence, rather than calling for more research scrutinizing the comprehensiveness of the literature exposition, we see it as more important to study and evaluate what results can be gained by organizations adopting more systemic and systematic approaches to innovation management. Important aspects include the influence such approaches may have on the type of innovation that are generated and how they affect innovation efficiency and effectiveness. There are, of course, also potential downsides with systemic and systematic approaches to innovation management, as these may hamper innovation activities if they are not questioned and improved.

\section{Implications for practice}

The systems approach to innovation management provides companies and organizations with a guiding framework that can serve as a checklist of what elements should be considered to improve innovation performance and capabilities. It can help organizations move beyond simplistic and episodic efforts and adopt a more systemic, systematic and sustainable approach. A systems approach can also form the basis for innovation management assessments, management reviews and maturity models to assist organizations in identifying critical issues and developing action plans. 
With the emerging system frameworks at the European and international level, common and more credible reference frameworks are established. They can be used for independent audits of an organization, benchmarking and comparisons between organizations, as well as for providing innovation management support and consulting services.

Commonly shared system frameworks and a common language for innovation management can help facilitate awareness and drive the adoption and integration of innovation activities in all management practices of any organization.

\section{References}

Adner, R. and Kapoor, R. (2010).Value creation in innovation ecosystems: how the structure of technological interdependence affects firm performance in new technology generations. Strategic Management Journal, 31(3), 306-333.

AENOR (2006). R\&D\&i management: R\&D\&i management system requirements. Spanish Standard UNE 166002, AENOR (Spanish version).

Amit, R. and Schoemaker, P. J. (1993). Strategic assets and organizational rent. Strategic Management Journal, 14, 33-46.

Ashby, W. R. (1956). An introduction to cybernetics. London: Champan \& Hall.

Badrinas, J. and Vilà, J. (2015). An innovation management system to create growth in mature industrial technology firms. International Journal of Innovation Science, 7(4), 263-279.

Barney, J. B. (1991). Firm resources and sustained competitive advantage. Journal of Management, 17, 99-120.

Bean, R. and Radford, R.W. (2001). The business of innovation: managing the corporate imagination for maximum results. New York: AMACOM.

Bhidé, A. (2000). The origin and evolution of new businesses. New York: Oxford University Press.

Blank, S. (2013). Why the lean start-up changes everything. Harvard Business Review, 91(5), 63-72.

Bogers, M., Zobel, A-K., Afuah, A., Almirall, E. Brunswicker, S., Dahlander, L., Frederiksen, L., Gawer, A., Gruber, M., Haefliger, S., Hagedoorn, J., Hilgers, D., Laursen, K., Magnusson, M., and Majchrzak, A., McCarthy, I. P., Moeslein, K. M. and Nambisan, S., Piller, F.T., Radziwon, A., Rossi Lamastra, C., Sims, J. and Ter Wal, A. L. J. (2017). The open innovation research landscape: established perspectives and emerging themes across different levels of analysis, Industry and Innovation, 24(1), 8-40.

Brown, S. L. and Eisenhardt, K. M. (1998). Competing on the edge: strategy as structured chaos. Boston, MA: Harvard Business School Press.

BSI (2008). Design management systems - part 1: guide to managing innovation. British Standard BS 7000-1:2008, BSI.

Burgelman, R.A. (1983). Corporate entrepreneurship and strategic management: insights from a process study. Management Science, 29(12), 1349-1364.

Burns, T. and Stalker, G. M. (1961). Management of innovation. London: Tavistock Publications.

Caetano, I. (2017). Standardization and innovation management. Journal of Innovation Management, 5(2), $8-14$.

CEN (2013). Innovation management - part 1: innovation management system. CEN/TS 16555-1.

Chen, J., Jin, X., He, Y.-B. and Yao, W. (2006). TIM based indigenous innovation: experiences from Haier Group. 2006 IEEE International Conference on Management of Innovation and Technology, 207-210, June 21-23, Singapore.

Chen, J., Yin, X. and Mei, L. (2018). Holistic innovation: an emerging innovation paradigm. International Journal of Innovation Studies, 2(1), March, 1-13.

Cigaina, M. (2013). Innovation management framework: enabling and fostering innovation in your company. Epistemy Press.

Clark, K. B. and Fujimoto, T. (1990). The power of product integrity. Harvard Business Review, 68(6), 107-118.

Cohen, D., Lindvall, M. and Costa, P. (2003). A state of the art report: agile software development, data and analysis center for software 775 Daedalian Dr. Rome. New York 13441-4909.

Cooper, R. G. (1990). Stage-gate systems: a new tool for managing new products. Business Horizons, 33(3), May-June, 44-54.

Cusumano, M. and Nobeoka, K. (1998). Thinking beyond lean: how multi-project management is transforming Toyota and other companies. New York: The Free Press. 
Cusumano, M. A. and Gawer, A. (2002). The elements of platform leadership. MIT Sloan Management Review, 51-58.

Drucker, P. F. (1985). Innovation and entrepreneurship: practices and principles. New York: Harper \& Row.

Erickson, L. B. (2015). The innovator's method: bringing the lean startup into your organization. ResearchTechnology Management, 58(1), January-February.

Garechana, G., Río-Belver, R., Bildosola, I. and Salvador, M. R. (2017). Effects of innovation management system standardization on firms: evidence from text mining annual reports. Scientometrics, 111, 1987-1999.

Geissdoerfer, M., Bocken, N. M. P. and Hultink, E. J. (2016). Design thinking to enhance the sustainable business modelling process - a workshop based on a value mapping process. Journal of Cleaner Production, $135,1218-1232$.

Goffin, K. and Mitchell, R. (2005). Innovation management: strategy and implementation using the pentathlon framework (1st ed.). London: Palgrave Macmillan.

Grant, R. M. (1991). A resource based theory of competitive advantage: implications for strategy formulation. California Management Review, 33, 114-135.

Hakes, C. (2014). Innovation reboot: how to build, manage and assess innovation capability in organisations and teams. Somersham: Leadership Agenda Limited, The Innovation Reboot Project.

Hamel, G. and Prahalad, C. K. (1994). Competing for the future. Boston, MA: Harvard Business School Press.

Hart, M. (2012). The lean startup: how today's entrepreneurs use continuous innovation to create radically successful businesses. Journal of Product Innovation Management, 29(3), 506-510.

Henderson, R. M. and Clark, K. B. (1990). Architectural innovation: the reconfiguration of existing product technologies and the failure of established firms. Administrative Science Quarterly, 35, 9-30.

Hollins, B. (2000). The development of a British standard for innovation management. The Design Journal, $3(2), 27-35$.

Holt, K., Geschka, H. and Peterlongo, G. (1984). Need assessment: a key to user-oriented product innovation. New York: John Wiley \& Sons Ltd.

ISO (2015). Quality management systems - requirements. International Standard, ISO 9001:2015.

Janszen, F. (2000). The age of innovation. London: Prentice Hall.

Katz, D. and Kahn, R. L. (1966). The social psychology of organizations. New York: John Wiley \& Sons Ltd.

Kline, S. J. (1985). Innovation is not a linear process. Research Management, 28(4), 36-45.

Lawrence, P. R. and Lorsch, J.W. (1967). Organization and environment: managing differentiation and integration, Division of Research, Graduate School of Business Administration. Boston, MA: Harvard University Press.

Lawson, B. and Samson, D. (2001). Developing innovation capability in organisations: a dynamic capabilities approach. International Journal of Innovation Management, 5, 377-400.

Liker, J. K. (2004). The Toyota way: fourteen management secrets from the world's greatest manufacturer. New York: McGraw-Hill.

Lorenzoni, G. and Lipparini, A. (1999). The leveraging of interfirm relationships as a distinctive organizational capability: a longitudinal study. Strategic Management Journal, 20(4), 317-338.

Luebkeman, C. and Brown, T. (2015). Design is our answer an interview with leading design thinker Tim Brown. Architectural Design, 85, 34-39.

Magnusson, M. and Pasche, M. (2014). A contingency-based approach to the use of product modules and platforms. Journal of Product Innovation Management, 31(3), 434-450.

Mao, W. and Wang, P. (2012). Innovation management in Japanese Electronics Companies: a perspective of Total Innovation Management (TIM). Proceedings of the 2012 IEEE ISMOT, 518-521, November 8-9, Hangzhou, Zheijiang, China.

March, J. G. (1991). Exploration and exploitation in organizational learning. Organization Science, 2(1), February.

Martinich, L. (2004). An innovation framework: the foundation for two complementary approaches to innovation management. IEEE/UT Engineering Management Conference, August 12-13, Austin, TX.

McGrath, R. G. (2010). Business models: a discovery driven approach. Long Range Planning, 43, 247-261.

Menke, M., Xu, Q. and Gu, L. (2007). An analysis of the universality, flexibility, and agility of total innovation management: a case study of Hewlett - Packard. Journal of Technology Transfer, 32, 49-62.

Microsoft. (2013). Best practices for innovation: Microsoft's innovation management framework, Microsoft, June 2013.

Mintzberg, H., Ahlstrand, B. and Lampel, J. (1998). Strategy safari: a guided tour through the wilds of strategic management. New York:The Free Press. 
Mir, M. and Casadesús, M. (2011). Standardised innovation management systems: a case study of the Spanish Standard UNE 166002:2006. Revista Innovar Journal, 21(40), 171-187.

Mir, M., Casadesús, M. and Petnji, L. H. (2016). The impact of standardized innovation management systems on innovation capability and business performance: an empirical study. Journal of Engineering Technology Management, 41, 26-44.

Mugge, P. and Markham, S. K. (2013). An innovation management framework: a model for managers who want to grow their businesses. In Kahn, Kenneth B. (Ed.), The PDMA handbook of new product development. New York: John Wiley \& Sons Ltd.

Muramatsu, R., Ichimura, T. and Ishii, K. (1990). An analysis of needs assessment and information behavior in product development based on the fusion model. Technovation, 10(5), 305-317.

Nagji, B. and Tuff, G. (2012). Managing your innovation portfolio. Harvard Business Review, 90(5), 66-74.

Nishiguchi, H. and Konno, N. (2018). Double-decker innovation management. Tokyo: Nikkei Newspaper Publisher.

Nonaka, I. (1994). A dynamic theory of organizational knowledge creation. Organization Science, 5(1), 14-37.

O'Connor, G., Leifer, R., Paulson, A. and Peters, L. (2008). Grabbing lightning: building a capability for breakthrough innovation. San Francisco, CA: Jossey-Bass.

O'Connor, G. C., Corbett, A. C. and Peters, L. S. (2018). Beyond the champion: institutionalizing innovation through people. Stanford: Stanford University Press.

Oh, D. S., Phillips, F., Park, S. and Lee, E. (2016). Innovation ecosystems: a critical examination. Technovation, $54,1-6$.

PDMA \& TIM (2013). Innovation Management Standard, TIM-PD-001-STD, Product Development and Management Association (PDMA), Total Innovation Management (TIM) Foundation.

Porter, M. E. (1980). Competitive strategy: techniques for analyzing industries and competitors. New York: Free Press.

Prahalad, C. K. and Hamel, G. (1990). The core competence of the corporation. Harvard Business Review, May-June, 79-91.

Rebelo, M. F., Santos, G. and Silva, R. (2015). Integration of standardized management systems: a dilemma? Systems, 3, 45-59.

Reinertsen, D. G. (1999). Taking the fuzziness out of the fuzzy front end. Research Technology Management, November-December, 25-31.

Ries, E. (2011). The lean startup: how today's entrepreneurs use continuous innovation to create radically successful businesses. New York: Crown Business.

Schilling, M. A. (2010). Strategic management of technological innovation (4th ed., international version). New York: McGraw-Hill.

Scott,W. R. (1981). Organizations: rational, natural and open systems. Englewood Cliffs, NJ: Prentice-Hall.

Senge, P. M. (1990). The fifth discipline. The art and practice of the learning organization. London: Random House.

Shapiro, S. M. (2001). 24/7 Innovation: a blueprint for surviving and thriving in an age of change. New York: McGraw Hill.

Simon, H. A. (1947). Administrative behavior (1st ed.). New York: Free Press,.

Skarzynski, P. and Gibson, R. (2008). Innovation to the core: a blueprint for transforming the way your company innovates. Boston, MA: Harvard Business School Press.

Taylor, A. and Wagner, K. (2014). Rethinking your innovation system. Boston Consulting Group, October.

Teece, D. J. (2007). Explicating dynamic capabilities: the nature and microfoundations of (sustainable) enterprise performance. Strategic Management Journal, 28(13), 1319-1350.

Teece, D. J., Pisano, G. and Shuen, A. (1997). Dynamic capabilities and strategic management. Strategic Management Journal, 18, 509-533.

Thompson, J. D. (1967). Organizations in action. New York: McGraw Hill.

Tidd, J. and Bessant, J. (2013). Managing innovation: integrating technological, market and organizational change (5th ed.). New York: John Wiley \& Sons Ltd.

Tidd, J., Bessant, J. and Pavitt, K. (1997). Managing innovation: integrating technological, market and organizational change (1st ed.). New York: John Wiley \& Sons Ltd.

Tucker, R. B. (2002). Driving growth through innovation: how leading firms are transforming their futures. San Francisco: Berrett-Koehler Publishers Inc.

Tuominen, M., Piippo, P., Ichimura, T. and Matsumoto, Y. (1999). An analysis of innovation management systems' characteristics. International Journal of Production Economics, 60-61, 135-143.

Tushman, M. L. and O'Reilly, C. A. (1996). Ambidextrous organizations: managing evolutionary and revolutionary change. California Management Review, 38(4), 8-30. 


\section{Magnus Karlsson and Mats Magnusson}

van de Ven, A. H., Polley, D. E., Garud, R. and Venkataraman, S. (1999/2008). The innovation journey. New York, NY: Oxford Univ. Press.

Vilà, J. and Muñoz-Nájar, J. A. (2002). The innovation system: organizational and managerial competencies to innovate. IESE Alumni Magazine, March.

von Stamm, B. (2003). The innovation wave: meeting the corporate challenge. New York: John Wiley \& Sons Ltd. Wernerfelt, B. (1984). A resource-based view of the firm. Strategic Management Journal, 5, 171-180.

Xu, Q., Chen, J., Xie, Z., Liu, J., Zheng, G. and Wang,Y. (2007). Total innovation management: a novel paradigm of innovation management in the 21st century. Journal of Technology Transfer, 32, 9-25.

Xu, Q.,Yu, Z., Zheng, G. and Zhou, Z. (2002). Towards capability-based Total Innovation Management (Tim): the emerging new trend of innovation management - a case study of Haier Group. ISMOT \& ICMIT'02, Hangzhou, Zhejiang, China: Zhejiang University Press.

Xu, Q., Zhu, L., Zheng, G. and Wang, F. (2007). Haier's Tao of innovation: a case study of the emerging total innovation management model. Journal of Technology Transfer, 32, $27-47$.

Yepes, V., Pellicer, E., Alarcon, L. F. and Correa, C. L. (2016). Creative innovation in Spanish construction firms. Journal of Professional Issues in Engineering Education and Practice, 142, 1. 